\title{
Autoria e deontologia: mediação de princípios éticos e práticas de letramento na escrita acadêmica em um fórum virtual
}

\author{
Authorship and Deontology: Mediation of \\ Ethical Principles and Literacy Practices in \\ Academic Writing Using a Virtual Forum
}

Júlio César Araújo*

Universidade Federal do Ceará

Fortaleza - Ceará / Brasil

Messias Dieb**

Universidade Federal do Ceará

Fortaleza - Ceará / Brasil

\begin{abstract}
RESUMO: Este artigo analisa a utilização de um fórum virtual como alternativa de interação entre professores, estudantes e bolsistas nas disciplinas Leitura e Produção de Textos Acadêmicos (LPTA) e Metodologia Científica, dos cursos de Letras e Pedagogia, respectivamente, da Universidade Federal do Ceará - UFC. A questão investigada é: Como a interação no fórum virtual pode alavancar a aprendizagem da escrita de textos acadêmicos e promover a construção de uma consciência deontológica inerente a essa atividade? Os resultados mostraram que, no ambiente virtual, os alunos discutiram suas dificuldades relativas à escrita acadêmica e se descobriram autores de artigos científicos e projetos de pesquisa, evitando a apropriação indevida de ideias alheias e estabelecendo relações cooperativas e respeitosas para com as dificuldades de escrita do outro. Assim, o fórum se mostrou bastante útil à exploração dos conteúdos de ambas as disciplinas, enriquecendo a interação respeitosa, os letramentos e a autoconfiança dos alunos. PALAVRAS-CHAVE: Letramento; aprendizagem; fórum virtual; interação virtual; escrita acadêmica.
\end{abstract}

* araujo.ufc@gmail.com

**mhdieb@gmail.com 
ABSTRACT: This article analyzes the use of a virtual forum as an option for the interaction between professors, students and fellows in two undergraduate programs at the Federal University of Ceará - Brazil: a) Literature and Languages and b) Pedagogy, respectively. The question investigated is: How can the interaction on the virtual forum improve the learning of academic text production and promote the construction of a deontological conscience inherent to this activity? The results showed that, in the virtual environment, the students discussed their difficulties related to academic writing and discovered themselves as authors of scientific articles and research projects, avoiding the undue appropriation of ideas of other people, and establishing cooperative and respectful relationships concerning the difficulties of writing of the other students. Thus, the forum has represented an additional possibility in the exploitation of contents in both courses, enriching the respectful interaction, the literacies and the selfconfidence of the students.

KEYWORDS: Literacy; learning; virtual forum; virtual interaction; academic writing.

\section{Introdução}

$\mathrm{Na}$ condição de professores, quando falamos sobre o tema da leitura e da escrita, logo nos vem à mente grande preocupação com a fragilidade demonstrada pela maioria de nossos alunos, da educação básica ao ensino superior, acerca dos usos efetivos dessas atividades em situações reais de interação, ou seja, a fragilidade de realizar práticas de letramento bem-sucedidas (BARTON; HAMILTON, 2000). Esse fato se justifica porque pouco são os gêneros de texto com os quais os estudantes conseguem estabelecer uma comunicação satisfatória, especialmente se o que estiver sendo analisado for o estilo da escrita e a organização retórica do próprio gênero. Do mesmo modo, se observarmos as estratégias discursivas por eles apresentadas, a situação pode demandar uma inquietação maior ainda.

Sob esse aspecto, não é novidade afirmarmos que a formação de estudantes para serem bons produtores de texto, e leitores proficientes dos mais variados gêneros textuais, que circulam na sociedade e, mais restritamente, na esfera acadêmica, tais como resumos, resenhas e artigos, tem sido bastante difícil para aquela que ainda representa a nossa principal agência de letramento: a escola. Com base nessa realidade, e em função de nossa experiência de professores em disciplinas da graduação que tratam especificamente da redação acadêmica, buscamos analisar apropriações que estudantes recém-ingressos na universidade realizam acerca da escrita dos gêneros de textos próprios desse espaço de interação, assim como algumas características deontológicas que marcam fortemente essa atividade de escrita. Em termos mais específicos, o 
que buscamos analisar, por meio deste trabalho, é a consciência deontológica que esses estudantes constroem acerca do ato de escrever de acordo com as normas estabelecidas e praticadas pela comunidade acadêmica, uma vez que a aprendizagem das funções comunicativas, cognitivas e institucionais, bem como as peculiaridades linguísticas e estruturais relativas aos gêneros praticados na academia representa, às vezes, uma conquista bastante árdua para os alunos advindos da educação básica.

Apesar de o objetivo anunciado, acima, estar sendo alcançado em forma de texto apenas recentemente, ele já vem sendo perseguido há algum tempo na prática da sala de aula. Nessa direção, faz-se necessário salientar que, apesar de não compor o corpus que será por nós analisado neste artigo, os primeiros passos dados na direção do objetivo que aqui nos propomos a alcançar reportam à realização de uma pequena enquete ${ }^{1}$ no ano de 2008 , com estudantes recém-chegados ao curso de Letras da Universidade Federal do Ceará, matriculados na disciplina Leitura e Produção do Texto Acadêmico (LPTA). Assim sendo, fazer menção a essa enquete, realizada em sala de aula como um diagnóstico sobre os alunos do referido ano, serve-nos tão somente como ponto de partida para uma construção argumentativa que justifique nosso empreendimento no presente trabalho.

Por meio da citada enquete, obtivemos a informação de que $89 \%$ dos alunos tinham dificuldades para produzir um texto e/ou assumiam não gostar de escrever. Descobrimos ainda que sua maior angústia em relação ao ato de escrever era a de não conseguir oferecer informaçōes claras ao leitor, isto é, a de não tornar compreensível aquilo que escreviam. Além disso, 22\% dos estudantes declararam que não buscavam alternativas para superar tal dificuldade, pois o sentimento de fracasso produzido por essa situação fazia com que eles desistissem de persistir em busca dessa finalidade. Assim sendo, o desafio frente ao qual nos colocava a disciplina LPTA era, e ainda é, extremamente sério, haja vista a necessidade de tornarmos a tarefa de escrever menos difícil e mais significativa para aqueles estudantes.

Em função dessa necessidade e a partir de outro dado da enquete, o de que $92 \%$ dos alunos matriculados acessavam a internet e nela faziam uso da escrita para se comunicar e para adquirir informações, decidimos utilizar, na referida disciplina, um fórum virtual ${ }^{2}$ por meio do qual os estudantes, com

${ }^{1}$ As questôes da enquete foram retiradas de Carla V. Coscarelli e Daniela Mitre (2007).

${ }^{2} \mathrm{O}$ fórum pode ser acessado por meio do link <http://lptaufc.forumn.net>. 
a ajuda do professor e dos monitores da disciplina, procuravam dar continuidade, via web, às aprendizagens iniciadas em sala de aula. A ideia do fórum foi de uma aluna, bolsista de iniciação à docência naquele período, a qual foi tão bem-sucedida que, atualmente, contabiliza mais de quinhentos membros inscritos no citado fórum, contando, entre eles, com estudantes até de outras universidades brasileiras. ${ }^{3}$

Desde 2008, o fórum passou a ser utilizado na disciplina LPTA, que é ofertada presencialmente, como mais um recurso de aprendizagem para os alunos. Em 2011, já tendo se consolidado como um forte componente didático, e em função do sucesso alcançado no que concerne à interação entre os participantes, decidimos ampliar o raio dessa interação envolvendo os alunos do curso de Pedagogia da Faculdade de Educação (Faced) da UFC. Essa decisão foi motivada pelo fato de na Faced a disciplina Metodologia Científica, que é igualmente ofertada de modo presencial, possuir ementa diferente, mas perseguir o mesmo objetivo, isto é, o de discutir sobre a atividade científica por excelência, a pesquisa, e ao mesmo tempo desenvolver habilidades de compreensão e produção de gêneros acadêmicos, como o artigo científico, no caso de LPTA, e o projeto de pesquisa em Metodologia Científica.

A partir dessa experiência, percebemos que uma das maiores preocupações dos estudantes centrava-se em como deveriam fazer referência aos autores em seus trabalhos e efetuar, por escrito, as citaçôes desses autores, sem que o uso de tais citaçôes insinuasse uma apropriação indevida do pensamento alheio. Esse fato nos fez perceber que, intimamente associado à aprendizagem do texto acadêmico, o fortalecimento da consciência dos alunos acerca da dimensão ética que perpassa essa atividade interativa mostrou-se igualmente necessário, devendo esse fortalecimento basear-se na construção e na vivência de valores socialmente estabelecidos, aceitos e praticados pelos membros da comunidade acadêmica. Dito de outra maneira, percebemos uma oportunidade de ampliarmos os letramentos desses aprendizes de gêneros de textos acadêmicos, considerando que eles passassem a respeitar não apenas as

\footnotetext{
${ }^{3}$ A aluna em questão é Carla Poennia Soares, bolsista de iniciação à docência da disciplina Leitura e Produção do Texto Acadêmico - LPTA, no curso de Letras da Universidade Federal do Ceará, no período de 2008 a 2009, e responsável não apenas pela criação do fórum estudado neste artigo, mas também pela sistematização dos dados aqui analisados (ver ARAÚJO; SOARES, 2009). A ela, agradecemos de maneira especial.
} 
regras que normalizam a forma dos textos, mas que se pautassem igualmente pelos valores que orientam a interação por meio desses textos, ou seja, por uma consciência deontológica quanto ao ato de escrever textos acadêmicos.

Com base nisso, eis que surge a questão norteadora do presente trabalho: de que maneira a interação no fórum virtual pode alavancar a aprendizagem da produção escrita de textos acadêmicos e a construção de atitudes e comportamentos éticos inerentes a essa atividade? Ao discutirmos essa questão, nos foi instigada a defesa da seguinte tese: a ampliação da consciência deontológica que os alunos constroem acerca do ato de escrever, de acordo com as normas estabelecidas e praticadas pela comunidade acadêmica, implica igualmente a ampliação de seus letramentos, uma vez que na perspectiva dos novos estudos de letramento (STREET [1984]; [1988]; BARTON [1994]; BARTON; HAMILTON; IVANIE [2000]; SNYDER [2008]), e mais especificamente nas palavras de David Barton e Mary Hamilton, as práticas de letramento envolvem valores, atitudes, sentimentos e relações sociais, e são designadas por eles como "modos culturais universais de utilização da linguagem escrita nos quais as pessoas baseiam suas vidas" (BARTON; HAMILTON, 2000, p. 8, tradução nossa).

\section{A deontologia educacional e o ensino por meio de gêneros textuais}

De acordo com Santos (2008), boa parte dos professores parece ser frequentemente tomada por incertezas e inseguranças que os conduzem a um relativismo axiológico (variação constante de valores) e/ou a um neutralismo axiológico (invariância de valores). Em outros termos, o autor tenta explicar seu ponto de vista quanto ao uso dessas expressões dizendo, com base em Veiga (2005), que os professores tendem a evitar julgamentos sobre a sua conduta profissional, omitindo referências axiológicas, a fim de que não o venham responsabilizar pelo fato de seus alunos terem formado juízos de valor a partir de terem considerado válidas declarações que deles ouviram em sala de aula. Portanto,

numa escola em permanente mutação, que sofre constantes influências de culturas e ideologias diversas, a principal dificuldade com que se confronta, actualmente, o professor, [...], é a de saber que valores promover na sua actuação diária, quer, como salienta Tom $(1984),{ }^{[4]}$

${ }^{4}$ Alan Tom (1984). 
no nível do poder normativo - das atitudes e comportamentos que valoriza ou sanciona - quer no nível da gestão do currículo que lecciona e das metodologias educativas que adopta (SANTOS, 2008, p. 1).

Seguindo, pois, essa linha de raciocínio, vamos nos concentrar no segundo aspecto da assertiva acima, ou seja, nos valores que circundam a gestão do currículo e nas metodologias adotadas pelos professores, especialmente quanto ao ensino da língua e da linguagem.

Nesta direção, voltaremos às dificuldades que a escola tem enfrentado em relação ao ensino da leitura e da escrita, haja vista os efeitos dessa situação repercutirem em quase toda a vida estudantil dos sujeitos escolarizados. A nosso ver, essas dificuldades ocorrem porque a escola parece não compreender o que Lev S. Vygotsky (2000) teoriza acerca do exercício da escrita. Segundo esse pesquisador, a atividade da escrita não deveria ser ensinada como um exercício puramente mecânico, ou seja, uma ação com características mais motoras do que intelectuais, pois, assim tal qual a leitura, a escrita precisaria implicar algo de que as pessoas necessitassem, uma ação que pudesse expressar as suas atividades e que fizesse desabrochar a sua personalidade. Desse modo, a escola precisaria proporcionar aos aprendizes uma apropriação significativa da escrita, pautada no entendimento (na consciência) de que se trata apenas de outra forma de linguagem.

Por este motivo, o autor adverte que, mesmo sendo outra forma de linguagem, a escrita, tal como a fala, deveria ser apropriada por meio de um processo de uso real dessa atividade, em um conjunto de situações concretas de interação social, vividas pelas crianças, por exemplo, como "um momento natural no seu desenvolvimento" (VYGOTSKY, 2000, p. 144). Portanto, se 89\% dos estudantes, que participaram da enquete mencionada na introdução deste artigo, tinham dificuldades para produzir um texto e/ou assumiam abertamente que não gostavam de escrever, é presumível e pressuposto que a atividade de escrita tenha deixado de ter ou, quiçá, nunca tenha tido um significado (importância, valor, sentido) sensível e concreto para a vida desses sujeitos.

E onde entra o aspecto axiológico nesse fato? É simples! Os professores, quase sempre zelosos da tradição escolar, atropelam processos essenciais de aprendizagem da linguagem escrita. Esse fato se justifica na medida em que são guiados por certa representação de ensino de língua como ensino de gramática, ao mesmo tempo em que cedem a uma forte pressão dos pais para que as crianças aprendam cedo a escrever ortograficamente correto e que dominem com maestria as regras da gramática normativa. Devido a essa postura, é 
inevitável a constatação de que, mais do que promover o alargamento dos letramentos construídos pelos sujeitos, a escola tem se limitado apenas à prática tradicional da alfabetização, isto é, ao ensino do sistema alfabético, sem a reflexão acerca dos usos sociais que dele fazemos e/ou podemos fazer. Desta maneira, a escola acaba se configurando uma guardiā do neutralismo axiológico que tem cercado o ensino da leitura e da escrita.

E o que fazer? Ora, para que o processo de alfabetização, enquanto apropriação do sistema alfabético de escrita, não continue a se traduzir numa experiência escolar cuja ênfase esteja unicamente na "codificação" e "decodificação" de letras, palavras e até mesmo frases, sem que os sujeitos consigam construir sentido para a leitura e a escrita, é preciso que os professores compreendam que essa experiência também deve proporcionar aos estudantes a apropriação das múltiplas funções que a sociedade atribui àquelas atividades. É preciso, pois, construir e desenvolver múltiplos letramentos (O'BRIEN [1998]; KELLNER [1998]; [2004]; SOARES [2002]; ROJO [2009]).

Mesmo incluídos nesta perspectiva, não queremos de modo algum sugerir que dominar o código escrito e certas regras gramaticais não deva fazer parte da ampliação dos letramentos que devem ser ensinados pela escola. No entanto, vale lembrar, como bem adverte Ilana Snyder, que

quando a linguagem é vista como fixa e guiada por regras prescritivas, então a gramática formal é ensinada [basicamente] por meio de treinos e exercícios. Contudo, quando a linguagem é vista como dinâmica, mais facilmente aprendida por meio do uso, a gramática passa a ser ensinada como parte do processo de escrita, no momento da necessidade. (SNYDER, 2008, p. 159, tradução nossa).

Assim, uma das alternativas de que hoje temos conhecimento é a do ensino da linguagem escrita e da leitura a partir dos gêneros textuais (SWALES [1990]; SCHNEUWLY; DOLZ et al. [2004]). Os gêneros são, segundo Bakhtin (2000), enunciados relativamente estáveis, por meio dos quais a sociedade organiza sua comunicação, tais como, por exemplo: as cartas, os extratos e boletos bancários, os anúncios, os rótulos, as bulas de remédio, as notícias e reportagens dos jornais e da TV etc. $\mathrm{O}$ ensino baseado em gêneros se configura, pois, numa perspectiva de ensino em que os professores criem circunstâncias didáticas cuja intenção seja proporcionar aos estudantes a vivência de situações de comunicação o mais perto possível daquelas que temos na sociedade e que, desse modo, possam ter significado para eles. Para tornar os 
estudantes habilitados a darem respostas às demandas atuais de letramento, a escola precisa, com efeito, conectar o seu "universo de cultura escrita", como nos diz Lahire (1994, p. 20, tradução nossa), ao universo de relações que constituem esses sujeitos.

No caso dos gêneros ensinados em LPTA e Metodologia Científica, nosso compromisso ético se orienta pela necessidade de os estudantes, recémingressos na universidade, compreenderem que tais gêneros fazem parte de uma comunidade discursiva: a academia. Assim sendo, os gêneros acadêmicos envolvem um conjunto de eventos interativos e possuem propósitos comunicativos comuns a todos os membros dessa referida comunidade. Estes precisam, portanto, se tornar especialistas nas regras de comunicação que se estabelecem dentro dessa comunidade, compreendendo que tais regras "moldam a estrutura esquemática do discurso e influenciam e impóem limites à escolha de conteúdo e de estilo [dos gêneros que eles ordinariamente praticam]" (SWALES, 1990, p. 58, tradução nossa).

Em função dessas proposições de John M. Swales, apresentou-se para nós o grande desafio de tornar os alunos de LPTA e de Metodologia Científica especialistas nas regras de comunicação por meio dos gêneros de textos acadêmicos. Assim sendo, buscando evitar tanto o relativismo como o neutralismo axiológico de que nos fala Santos (2008), e tendo como base as ideias de Vygotsky (2000) em consonância com o que defendem Barton e Hamilton (2000, p. 8), tomamos a decisão de que o processo de aprendizagem dos nossos alunos precisava ser experienciado por eles como algo natural, em suas práticas cotidianas de escrita, de forma que os letramentos aí desenvolvidos estivessem permeados dos valores, atitudes, sentimentos e relações sociais próprios ao espaço acadêmico. Portanto, a compreensão e apropriação dessas regras, bem como dos valores que gravitam em seu entorno, constituem, desse modo, o que estamos aqui chamando de desenvolvimento de uma consciência deontológica sobre a produção textual na academia.

\section{As telas do fórum: captação e análise dos dados}

As imagens das telas do fórum foram obtidas por meio da tecla print screen do teclado e salvas, para análise, em arquivos DOC (extensão utilizada pelo aplicativo Word) no sistema operacional Windows. Para termos acesso a essas telas, tivemos, assim como todos os alunos, que nos registrar no fórum, lendo e aceitando os termos ali estabelecidos a fim de realizarmos o cadastramento necessário. Nesse processo, precisamos criar um login e uma 
senha e depois confirmar essas informaçōes através do endereço de e-mail fornecido ao cadastro. Somente após essas etapas é que o ambiente virtual do fórum nos permitiu participar das discussões, enviando e recebendo mensagens no decorrer das aulas.

Durante o andamento das duas disciplinas, nós, os moderadores do fórum (bolsistas e professores), participamos diariamente das discussões realizadas, esclarecendo dúvidas, estimulando a participação dos aprendizes por meio de questionamentos e/ou respondendo suas perguntas, dentre muitas outras atividades. $\mathrm{O}$ intuito era o de tornar as interações agradáveis e as discussões produtivas, de forma a evitar que os alunos se sentissem desanimados e/ou sozinhos. É importante frisar que, no ano de 2011, a aluna criadora do fórum já havia concluído o seu curso e não era mais bolsista da disciplina LPTA, porém, por ter sido idealizadora do uso daquela ferramenta virtual, continuava sendo colaboradora nas atividades que ali eram desenvolvidas.

$\mathrm{O}$ corpus que analisamos foi organizado obedecendo à cronologia da discussão sobre os temas propostos na disciplina, ou seja, as mensagens eram postadas pelos participantes de acordo com o assunto discutido em ordem cronológica e hierárquica, permitindo que todos tivessem acesso às mensagens "escritas" pelos demais membros. Dos assuntos abordados na disciplina LPTA, focalizamos no fórum a construção de um artigo acadêmico e as questôes que o cercam por ter sido este o gênero mais discutido e o conteúdo que gerou maior interação entre os alunos. Os dados refletem a sequência real das mensagens que contribuíram para as acaloradas discussões acerca da produção de textos científicos.

Tendo em vista que um artigo acadêmico prototípico é composto por cinco partes - Introdução, Metodologia, Fundamentação Teórica, Análise dos Dados e Conclusão -, organizamos as interações da seguinte maneira: a) primeiramente, os alunos recebiam explicações do professor, em sala de aula, sobre os movimentos retóricos mais comuns em cada parte do artigo e liam alguns trabalhos já publicados, a fim de se familiarizarem com o novo gênero; b) depois disso, eles deveriam produzir o seu próprio texto. Foi nesse momento que o fórum serviu como importante ferramenta para a construção de saberes e letramentos acadêmicos, pois os alunos, além de postarem seus questionamentos e trabalhos, tinham acesso também às dúvidas e informações fornecidas pelos outros colegas.

Com a inclusão da disciplina Metodologia Científica, o procedimento utilizado foi basicamente o mesmo, alterando-se apenas o gênero focado, pois 
agora os alunos estariam discutindo e aprendendo sobre o gênero projeto de pesquisa. Contudo, é relevante salientar que as preocupações e dúvidas continuavam relacionadas às mesmas questóes: citações, referências e "modos de dizer" por meio da escrita acadêmica. Levando em consideração que tanto o artigo científico como o projeto de pesquisa possuem sessões em comum, tais como a de fundamentação teórica e a de metodologia, a interação entre os alunos versava quase que exclusivamente acerca dessas partes comuns aos dois gêneros acadêmicos em tela.

De modo mais preciso, selecionamos catorze mensagens de um universo maior de 416, que foram extraídas do fórum. Essas catorze mensagens foram escolhidas a partir do critério de serem as mais representativas do conjunto das 416, pois deveriam apresentar alguma preocupação dos estudantes com questões éticas relativas ao trabalho de escrita. Assim, ao analisarmos as telas do fórum virtual, elaboramos cinco categorias acerca das principais preocupações dos alunos em relação à escrita do artigo científico e do projeto de pesquisa: 1) preocupação em buscar as fontes; 2) preocupação em como citar as fontes; 3) preocupação com o uso de informações; 4) preocupação em não se apropriar das ideias de outrem; e 5) preocupação em ser solidário com os colegas. Essas preocupações representaram, a nosso ver, o despertar para a formação de um processo de consciência deontológica, sendo esta relativa ao ato de escrever, especialmente no que concerne às normas de escrita praticada pela comunidade científica.

As normas de que estamos falando, no parágrafo anterior, podem ser perfeitamente associadas ao que Barton (1994), Barton, Hamilton e Roz Ivaniè (2000) e Brian V. Street (1984; 1988) sugerem quando afirmam que diferentes contextos da vida cotidiana apresentam diferentes demandas e percepçoes de letramento, diferentes níveis e tipos de poder social e de conhecimento, todos voltados para uma performance adequada dos indivíduos/sujeitos nesses diferentes contextos. Ao final da análise, foram selecionadas apenas seis telas para compor o presente texto, sendo estas as mais representativas de cada uma das cinco categorias elaboradas, segundo o nosso julgamento. Por questôes éticas cobrimos os nomes dos sujeitos que apareceram durante as interações com objetos do tipo retângulos ou linhas, preenchidos com a cor preta. No entanto, não realizamos o mesmo procedimento com as mensagens dos moderadores do ambiente virtual, porque todos estavam de acordo que seus nomes fossem revelados.

Para além das preocupaçóes com a atividade de escrita dos artigos e dos projetos, foi possível observar o carinho demonstrado pelos aprendizes de 
gêneros acadêmicos, no decorrer da interação com os colegas do fórum, com as monitoras das disciplinas e com os professores orientadores. Esse fator nos fez compreender que a formação de princípios éticos na aprendizagem de uma prática social, como a escrita, por exemplo, caminha lado a lado com as relações que são construídas nessa prática. Afinal, como já nos referimos acima, Barton e Hamilton (2000, p. 8) afirmam que as práticas de letramento sempre estão envolvidas por valores, atitudes, sentimentos e relaçôes sociais, a partir dos quais os sujeitos vão paulatinamente marcando sua presença no grande balé existencial da vida cotidiana e em suas inúmeras comunidades de discurso.

\section{Preocupação em buscar as fontes}

Ao se referir à interação por meio da escrita, Bakhtin atesta que "o discurso escrito é de certa maneira parte integrada de uma discussão ideológica em grande escala: ele responde a alguma coisa, refuta, confirma, antecipa as respostas e objeçóes potenciais, procura apoio, etc." (BAKHTIN, 1981, p. 123). Assim, para escrever um trabalho acadêmico, nossos alunos aprenderam que um autor deve saber dialogar com as vozes de outros pesquisadores para, a partir delas, pôr em cena o seu próprio projeto de dizer. Ao analisar os dados advindos das discussões no fórum virtual, percebemos, pois, que a interação entre os estudantes de graduação e os seus professores paulatinamente passou a influenciar-lhes na construção de saberes relativos ao discurso escrito como um ato de fala impresso, uma resposta, uma refutação, uma confirmação, uma antecipação ou qualquer outra atitude dialógica diante de tantos outros discursos que $\mathrm{o}$ antecederam.

Esse postulado bakhtiniano provocou nos aprendizes algumas atitudes éticas, entre as quais figurava a preocupação em buscar fontes com as quais deveriam dialogar durante o exercício da autoria em seus artigos e projetos de pesquisa. Mas, onde encontrar esse outro que, antes de nós, estudou o tema sobre o qual estamos também interessados? A tela abaixo apresenta o flagrante de um momento do fórum virtual em que uma estudante demonstrava a sua preocupação em citar a voz de outros autores em seu trabalho. Ela estava tendo dificuldades para conseguir esse material e, por isso, usou o fórum para compartilhar com os seus pares a apreensão por não estar conseguindo encontrar leituras adequadas ao seu trabalho.

A figura que segue ilustra um recorte da tela em que essa situação é ratificada. 


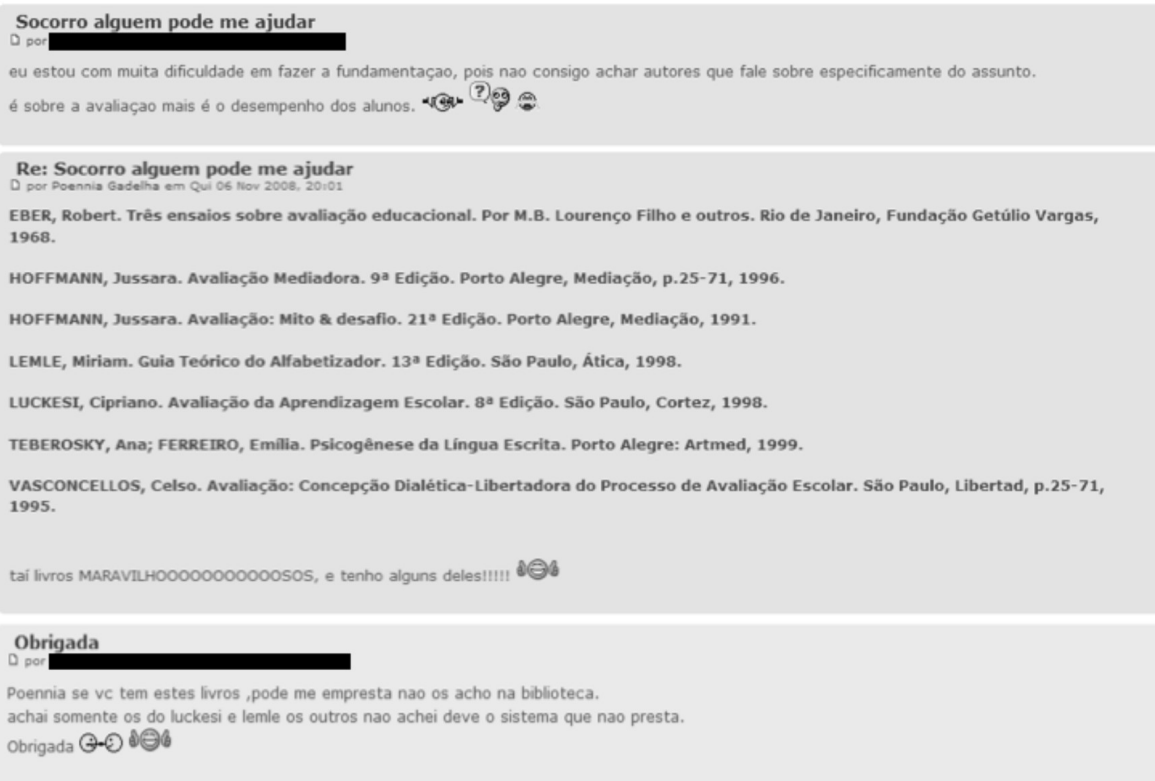

FIGURA 1 - Preocupação em buscar as fontes

Nesta figura é inequívoca a preocupação da aluna em conseguir leituras para fundamentar teoricamente o seu artigo. Esse fato revela indícios de letramento acadêmico na medida em que, pela sua participação no fórum virtual, demonstra ser necessário fazer uma revisão bibliográfica para proceder à escrita de seu próprio trabalho. Diante dessa preocupação, a bolsista da disciplina, que também fazia mediação pedagógica no fórum, fala da relevância de a aluna articular outras vozes na polifonia de sua produção acadêmica. Para facilitar o processo, portanto, a bolsista não apenas disponibilizou uma relação de autores, mas também se mostrou disponível para ajudar a aluna a conseguir esse material.

De posse da fonte, outra preocupação surge entre os alunos: como citar os teóricos dentro de seus trabalhos? Na sequência, discutiremos sobre esse saber acadêmico construído pelos estudantes.

\section{Preocupação em como citar as fontes}

Como sabemos, a redação científica é um texto regido por regras que ultrapassam os limites da formatação. Para além da formatação que, no caso do Brasil, é regida pela Associação Brasileira de Normas Técnicas (ABNT), os estudantes precisam compreender que um trabalho de pesquisa acadêmica é 
uma trama feita de vários fios advindos de enunciações plurais. Não basta, portanto, buscar as fontes, é necessário saber citá-las sob pena de se distanciar do ethos acadêmico que caracteriza a redação de gêneros científicos, como o artigo de pesquisa, a resenha, o resumo, o projeto, entre tantos outros textos praticados na universidade.

A figura a seguir explora a percepção dos graduandos acerca de suas inexperiências em relação a como devem fazer citações em seus textos.
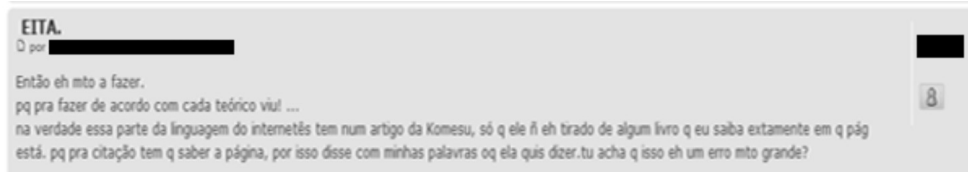

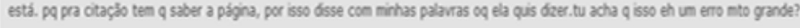

Estou com dúvidas nessa parte da análise.AJUDAAAAAAAA!

Quero saber como ponho esses trechos de poemas... se estão corretos e como me refiro a eles EX:No tópico sentimentos, temos o poema Amor tão Cruel, da acadêmica Beatriz Pinheiro, que está no livro Momentos Poéticos, página 104, primeira estrofe. POSE SER ASSIM? Preciso de dicas no resto tbm... Grato desde já.

FIGURA 2 - Preocupação em como citar as fontes

Ao olharmos para esta figura, observamos que o escasso conhecimento sobre como realizar a citação direta de um autor, ou a impossibilidade de fazê-lo corretamente, suscitam estratégias inteligentes nos alunos. A exemplo do tópico intitulado "EITA.", o uso de estratégias fica bem evidente quando a aluna afirma que, devido ao fato de não ter tido acesso ao número da página para poder concluir a citação direta, ela usou suas próprias palavras para dizer o que havia compreendido acerca do texto lido. Salta-nos, pois, de imediato aos olhos o fato de a estudante ter aprendido que, para não perder a ideia do autor, pode perfeitamente apelar para o recurso da paráfrase. Esta estratégia, se for bem utilizada, revela não apenas uma saída inteligente para o problema como também um exercício importante para o amadurecimento da autoria acadêmica e, obviamente, um forte indício de apropriação de práticas de letramento. Em consonância com as palavras de Marilia Amorim (2001, p. 201), o "texto relatante" é necessariamente outra enunciação, a qual exige certos princípios de sistematicidade.

Sobre esses aspectos, podemos dizer que o fórum virtual, além de servir de um produtivo meio de interação, nos ajudou a proporcionar a esses alunos a compreensão de que é preciso pensar melhor sobre o desafio de inscrever os dados construídos durante a pesquisa em outra enunciação: a que se discursiviza 
segundo "certos princípios de sistematicidade". Isso significa que, ao escrever seus artigos científicos, os alunos precisam trazer, não apenas os dados gerados, mas a voz dos autores lidos por eles para o interior de seu próprio texto. $\mathrm{O}$ mesmo ocorre em relação às leituras feitas com vistas à elaboração do texto da fundamentação teórica no gênero projeto de pesquisa, pois, ainda que o projeto seja de autoria dos estudantes, muitas das ideias ou conceitos que irão fundamentar a investigação pretendida são representativas de outras vozes, ou seja, de discursos de autoridade que eles trazem para dentro de seu texto.

Para melhor fazer bom uso das leituras, os alunos perceberam que não poderiam se desviar das normas acadêmicas, como as regras de citação, pois ao mesmo tempo em que o texto relatante está inserido em uma enunciação distinta daquela que gerou os dados, no caso do artigo científico, ele precisa fazer ecoar as vozes da realidade sócio-histórica da enunciação da escrita. No que concerne ao projeto de pesquisa, os alunos também desenvolveram essa percepção devido ao fato de que precisavam deixar claro para os seus leitores o que dizia a sua intenção de pesquisa e como esta intenção dialogaria com outros textos que foram produzidos anteriormente sobre o mesmo assunto. Nesse caso, o dialogismo entre vozes, tão necessário ao avanço de qualquer empreendimento sociodiscursivo, parece ter-se tornado uma aprendizagem efetiva para os estudantes das duas disciplinas aqui referidas.

Outro aspecto importante que a interação virtual no fórum mostrou diz respeito à preocupação em como usar os dados gerados na pesquisa de campo, especialmente na produção do artigo científico. Para isso, os estudantes tiveram de perceber e desenvolver outras atitudes deontológicas, a exemplo do respeito pelos informantes que colaboraram em suas pesquisas.

Preocupação com o uso de informaçōes

Como sabemos, fazer pesquisa no âmbito das ciências humanas significa adentrar, muitas vezes, a intimidade de certos agrupamentos sociais. Não é tarefa fácil entrar em um grupo de pessoas para executar um projeto de pesquisa, pois isso, muitas vezes, gera desconfiança nos sujeitos e, se o pesquisador não conseguir afiançar sua permanência no grupo, pode comprometer seu estudo. Nessas situaçóes, se os sujeitos sentirem que o pesquisador é uma pessoa de uma consistente postura ética, paulatinamente se abrirão à sua "invasão", pois perceberão que as açóes do pesquisador são guiadas por uma consciência deontológica que irá atravessar não apenas a enunciação da geração dos dados, mas, sobretudo, a enunciação da escrita do relatório da pesquisa. Embora ainda alunos da graduação, os sujeitos do nosso estudo se depararam com essa realidade, a qual éilustrada na figura subsequente. 


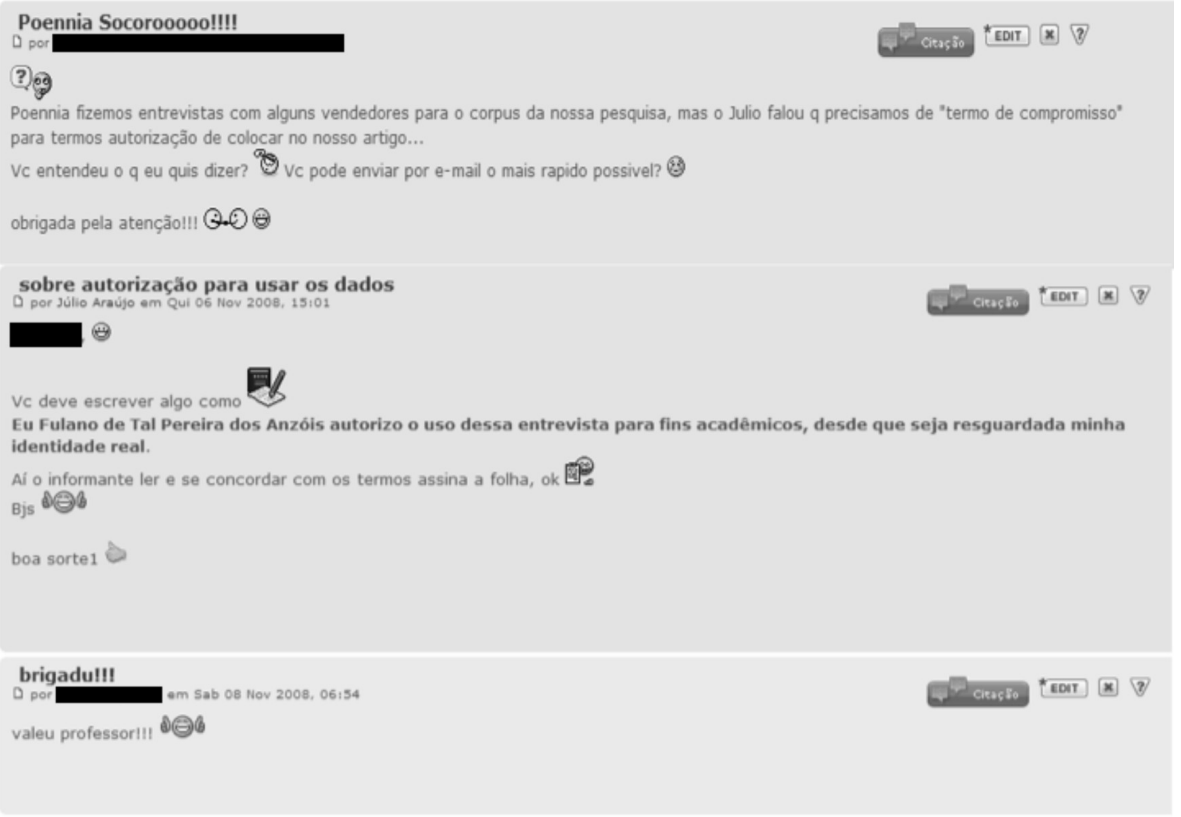

FIGURA 3 - Preocupação com o uso de informações

O fragmento da interação mostrado nessa figura desvenda traços de uma aprendizagem muito importante para quem deseja ser um bom redator de texto acadêmico: o respeito com os informantes. Os alunos passaram a compreender que uma das açóes mais respeitáveis, e que deve ser desempenhada pelo pesquisador, é a de conseguir o livre consentimento de seus colaboradores, para o uso ético dos dados que emergiram do encontro entre ele e os seus sujeitos. A ciência deste acordo sinaliza, indubitavelmente, para um saber-fazer acadêmico típico de um sujeito que avançou em termos de práticas letradas nessa área, já que corrobora a transposição da cena da geração de dados para a cena descrita ou projetada nos gêneros de texto acadêmico, como o artigo ou o projeto de pesquisa, respectivamente, em especial no que concerne aos aspectos metodológicos desse saber-fazer.

Além de desenvolver o respeito pelos colaboradores da pesquisa, nossos alunos entenderam que, no Brasil, o plágio é crime. ${ }^{5}$ Sobre esse aspecto, discutiremos a seguir.

${ }^{5}$ A Lei n0 9.610, de 19 de fevereiro de 1998 protege os direitos autorais e condena o plágio. 


\section{Preocupação em não se apropriar das ideias de outrem}

Nossos estudantes, ao longo da interação no fórum e em sala de aula, foram percebendo que não lhes bastavam saber procurar informações, saber citá-las dentro de seus textos e saber respeitar os informantes de suas pesquisas. Era preciso, inclusive, saber reger as vozes que formam a polifonia em que naturalmente se transforma qualquer produção científica. Nesse sentido, entenderam que não é ético abafar a voz autoral de algum trabalho que foi, indevidamente, citado no texto. Em outras palavras, é preciso tomar cuidado para dar os créditos a quem os merece.

A figura abaixo revela essa preocupação por parte dos alunos.

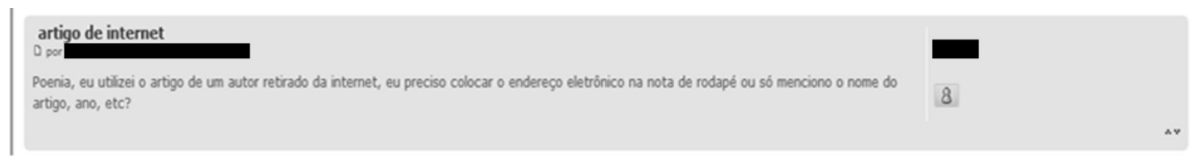

FIGURA 4 - Preocupação em não se apropriar das ideias do outrem

Por ser vasto, o conteúdo da internet oferece amplo acesso a textos acadêmicos que podem representar para alunos desonestos uma oportunidade de não exercer sua autoria. ${ }^{6}$ Nesse sentido, tem sido comum discutirmos durante as aulas sobre os perigos e as consequências, inclusive, judiciais do plágio. Para demonstrar que compreenderam a necessidade de desenvolver essa postura de natureza deontológica, foi comum encontrarmos no fórum virtual das disciplinas, postagens de alunos preocupados em apontar uma imagem de alguém que sabe fazer uso adequado do material que conseguiu ler na web.

No exemplo da FIG. 4, a locução verbal "preciso colocar" nos remete à consciência do dever-fazer que o aluno tem. Como pondera José Manuel F. dos Santos (2008), na deontologia educacional a pessoa, por meio do discurso, constrói uma imagem de si para tentar convencer os outros do seu valor em relação a dimensões socialmente apreciadas. Nesse sentido, as imagens que

\footnotetext{
${ }^{6}$ Além de buscadores como Google, os estudantes brasileiros têm livre acesso ao Portal de Periódicos da Capes (Coordenação de Aperfeiçoamento de Pessoal de Nível Superior). Isso significa que o governo federal do Brasil oferece acesso aos textos completos de artigos selecionados de mais de 21.500 revistas nacionais e estrangeiras, de reconhecido mérito acadêmico. Para outras informações, consultese o site do governo <www.periodicos.capes.gov.br>.
} 
emergem da análise que fizemos da interação no fórum virtual não se reduzem apenas à preocupação de não se assenhorar indevidamente de ideias alheias, mas se espraiam ainda na direção de uma apreciável virtude humana: a solidariedade.

\section{Preocupação em ser solidário com os colegas}

O processo de descoberta da autoria por meio do exercício da pesquisa e da escrita de gêneros acadêmicos é espinhoso para a maioria dos alunos da graduação. Nossa experiência didática com o fórum, contudo, nos autoriza a afirmar que o uso desse gênero de texto virtual serviu para, além de ser um espaço alternativo de aprendizagem da escrita acadêmica, aproximar os alunos entre si, suscitando, em função desse contexto, a interpretação da solidariedade entre eles como um comportamento de caráter quase deontológico.

Sobre isso, observemos a figura abaixo em que se evidencia uma conversa dos estudantes envolvendo a troca de seus textos, fato que os levou a descobrir também a autoria no exercício de atuar como leitor dos textos uns dos outros.

\section{Metodologia Suada!}

El.... Alguém pode ler minha metodologia, antes que eu entregue p/professor?? Só deu uma página, tem algum problema? $(-)$

Re: Ajuda

Claroo... só se for agora mesmo! Manda aí! Ah... ñ tm problema em ser pequena ñ $($ ) Valeuu

Manda aí a tua tb.... Nem sei o ki seria de mim sem isso! ( $6 / 0$ (a)

FIGURA 5 - Preocupação em ser solidário com os colegas 


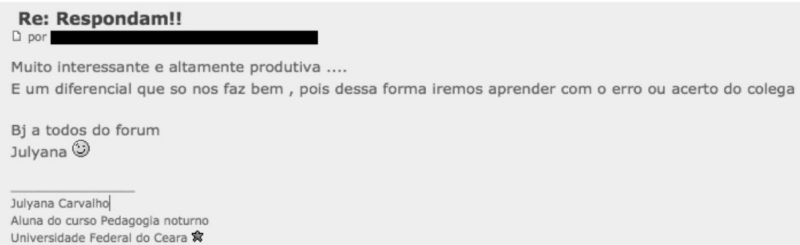

O tópico "Metodologia suada", o qual nos chamou bastante a atenção, remete-nos para a ideia de um trabalho que exigiu um grande esforço físico. Podemos interpretá-lo como sendo um qualificativo pelo qual os alunos descreveram sua experiência em relação à escrita da metodologia, seja do artigo científico ou do projeto de pesquisa. Para eles, parece ter sido uma atividade extenuante dar conta de uma metodologia adequada aos objetivos de suas pesquisas e transpor a organização dessas informações para o texto que estavam produzindo. A partir da análise das postagens no fórum, inferimos que esta situação lhes exigiu esforço para a execução de uma atividade que, se estivessem sozinhos, seria bem mais complicada de ser realizada. Nesse sentido, a interação no fórum virtual permitiu que eles postassem seus textos nesse ambiente, a fim de que os demais colegas pudessem ler o seu trabalho, ajudando-os a chegarem a uma versão mais consistente, quando deveriam submetê-la ao crivo de seus professores.

As postagens ilustradas pelas FIG. 5 e 6 parecem lembrar ainda verdadeiros depoimentos, por parte dos estudantes, acompanhados de sinceras manifestações de agradecimento. O que nos interessou realmente nesses escritos foi a avaliação que eles acabaram fazendo do processo de elaboração da metodologia de seus trabalhos, chamando-nos a atenção para o fato de que, para eles, paralelamente à aprendizagem a partir do "erro" constatado no trabalho de um colega caminha a dificuldade de externar esse "erro" para o 
referido colega. A troca desses textos entre os alunos revelou o desenvolvimento de um comportamento solidário e ético que se exprimiu, com efeito, em bons trabalhos, cuja versão final revelou uma escrita cuidadosa, além de um perfil de redatores bem menos problemático do que aquele revelado pela enquete aplicada no ano de 2008.

\section{Considerações finais}

Neste artigo, analisamos a interação entre professores, estudantes e bolsistas nas disciplinas LPTA e Metodologia Científica, ministradas pelos autores deste artigo na Universidade Federal do Ceará, respectivamente nos cursos de Letras e Pedagogia. Nessas duas disciplinas, a utilização de um fórum virtual se constituiu como alternativa eficaz para que os alunos desenvolvessem uma maior aprendizagem acerca da produção de gêneros acadêmicos e ampliassem sua consciência sobre os valores que norteiam essa prática de escrita. Embora em nossa produção científica já se encontrem algumas reflexões sobre a mediação pedagógica com o uso de novas tecnologias da informação e comunicação, neste trabalho avançamos no sentido de pensar sobre os valores que se agregam aos letramentos desenvolvidos por meio dessa mediação (ARAUJO; DIEB, 2010). Nesse sentido, os dados mostraram que a interação no fórum apontou para a construção de uma identidade autoral ética que foi se edificando ao longo do processo de aprendizagem, revelando-se imprescindível para a legitimação social dos estudantes como produtores de textos acadêmicos, ou seja, como sujeitos que começaram a dominar, com propriedade e consciência deontológica, as práticas de letramento nesse espaço de interação que é a universidade.

Os elementos mais salientes dessa identidade autoral se fizeram perceber nas preocupaçôes demonstradas pelos discentes em: a) buscarem as fontes mais confiáveis para a fundamentação teórica de seus artigos e projetos de pesquisa; b) saberem fazer bom uso das informações que essas fontes lhes disponibilizam; c) saberem citar corretamente, de acordo com as normas da $\mathrm{ABNT}$, as fontes consultadas; d) não se apropriarem indevidamente das ideias dos autores lidos; e, por fim, e) serem solidários com os colegas que demonstraram essas e outras dificuldades no decorrer da interação no fórum.

Os dados mostraram ainda que quando os alunos passam a perceber, com clareza, a dimensão deontológica subjacente ao trabalho de pesquisa que estão a realizar, seus textos se alteram em qualidade e fidedignidade. $\mathrm{Na}$ 
situação analisada, as práticas interativas ambientadas na web fortaleceram ainda mais a linkagem entre ensino e aprendizagem, salientando, sobremaneira, os aspectos éticos envolvidos nesses processos. Desta maneira, gêneros textuais virtuais, como o fórum, podem ser reveladores dos bastidores de uma aprendizagem que tende a ganhar feiçôes cada vez mais colaborativas, mais respeitosas e mais deônticas por parte dos alunos. Além disso, o uso da ferramenta virtual ratificou para nós as proposições de Colin Lankshear, Snyder e Bill Green quando afirmam que, "se forem abordadas com sensibilidade e bom senso, as novas tecnologias oferecem aos professores grandes possibilidades para inovação e renovação profissional, tão importantes quanto novas possibilidades de aprender [com elas]" (LANKSHEAR; SNYDER; GREEN, 2000, p. 2, tradução nossa).

Se compararmos os resultados aqui analisados com os daquela enquete diagnóstica, que aplicamos em 2008, é notória e satisfatória a mudança de atitude dos alunos frente ao desafio de aprender a escrever e de se tornarem partícipes ativos em relação aos múltiplos letramentos que a leitura e a produção de textos acadêmicos exigem. Nas palavras de Len Unsworth, as pessoas "precisam entender como os recursos de linguagem, imagem e de retórica digital podem ser implantados independentemente e interativamente para construir diferentes tipos de significados" (UNSWORTH, 2001, p. 8, tradução nossa). Desse modo, ainda que não tenhamos explorado esses aspectos, os aprendizes usaram recursos multimodais, como os emoticons, para marcar seus sentimentos durante a interação. Vimos que, especialmente nas situações em que sentiram medo de "errar", eles precisaram gerenciar conflitos e, por isso, solicitaram ajuda, trocaram opiniōes e usaram "carinhas" como estratégias de polidez e de preservação de suas faces.

Nesse sentido, os alunos puderam participar de uma experiência de aprendizagem mais rica em valores e, certamente, mais proveitosa do ponto de vista da apropriação dos letramentos acadêmicos, haja vista as situaçôes ilustradas pelos dados, aqui analisados, terem proporcionado a eles também uma satisfatória vivência com as suas próprias emoções. Desse modo, a análise nos permite concluir que quando buscamos garantir a qualidade ética e deontológica nas situaçôes de aprendizagem, tal como fizemos na de gêneros acadêmicos, essa preocupação tributa grande ajuda para a formação dos aprendizes, levando-os a se tornarem "pessoas responsáveis pelos seus actos e capazes de assumir essa responsabilidade" (SANTOS, 2008, p. 2) ao longo de suas vidas, conforme é o nosso desejo. 


\section{Referências}

AMORIM, M. O pesquisador e seu outro: Bakhtin nas ciências humanas. São Paulo: Musa, 2001.

ARAÚJO, J. C.; DIEB, M. Interação virtual e a autoria de artigos científicos: nos bastidores da produção acadêmica. Educação em Revista, Belo Horizonte, v. 26, n. 3, p. 387-406, dez. 2010.

ARAÚJO, J. C.; SOARES, C. P. G. Nos bastidores digitais da aprendizagem de leitura e produção de texto acadêmico. Formas \& Linguagens, Ijuí, ano 8, n. 17, p. 53-74, jan.-jun. 2009.

BAKHTIN, M. Marxismo e filosofia da linguagem: problemas fundamentais do método sociológico na ciência da linguagem. São Paulo: Hucitec, 1981.

BARTON, D. Literacy: an Introduction to the Ecology of Written Language. Cambridge (MA): Brackwell, 1994.

BARTON, D.; HAMILTON, M. Literacy Practices. In: BARTON, D.; HAMILTON, M.; IVANIÈ, R. Situated Literacies. London: Routledge, 2000. p. 7-15.

BARTON, D.; HAMILTON, M.; IVANIÈ, R. Situated Literacies. London: Routledge, 2000.

COSCARELLI, C. V.; MITRE, D. Oficina de leitura e produção de textos: livro do aluno. Belo Horizonte: Editora UFMG, 2007.

KELLNER, D. M. Multiple Literacies and Critical Pedagogy in a Multicultural Society. Educational Theory, Champaign, v. 48, n. 1, p. 103-122, 1998.

KELLNER, D. M. Revolución tecnológica, alfabetismos múltiples y la reestructuración de la educación. In: SNYDER, I. (Ed.). Alfabetismos digitales: comunicación, innovación y educación en la era electrónica. Archidona (Málaga): Aljibe, 2004. p. 227-250.

LAHIRE, B. Les raisons de l'improbable: les formes populaires de la "réussite" à l'école élémentaire. In: VINCENT, G. (Org.). L'éducation prisonnière de la forme scolaire? Scolarisation et socialisation dans les sociétés industrielles. Lyon: Presses Universitaires de Lyon, 1994. p. 73-106.

LANKSHEAR, C.; SNYDER, I.; GREEN, B. Teachers and Techno-Literacy: Managing Literacy, Technology and Learning in Schools. Sydney: Allen \& Unwin, 2000.

O’BRIEN, D. G. Multiple Literacies in a High School Program for "At-Risk" Adolescents. In: ALVERMANN, D. E.; HINCHMAN, K. A., MOORE, D. W.; PHELPS, S. F.; WAFF, D. R. (Ed.). Reconceptualizing the Literacies in Adolescents' Lives. Mahwah: Erlbaum, 1998. p. 27-49. 
ROJO, R. Letramentos múltiplos: escola e inclusão social. São Paulo: Parábola, 2009.

SANTOS, J. M. F. Valores e deontologia docente: um estudo empírico. Revista Iberoamericana de Educación, Madrid, v. 47, n. 2, p. 1-14, out. 2008.

SCHNEUWLY, B.; DOLZ, J. et al. Gêneros orais e escritos na escola. Tradução e organização de Roxane Rojo e Glaís Sales Cordeiro. Campinas: Mercado de Letras, 2004.

SNYDER, I. The Literacy Wars: Why Teaching Children to Read and Write is a Battleground in Australia. Sydney: Allen \& Unwin, 2008.

SOARES, M. Novas práticas de leitura e escrita: letramento na cibercultura. Educação \& Sociedade, Campinas, v. 23, n. 81, p. 143-160, dez. 2002.

STREET, B. V. Literacy in Theory and Practice. Cambridge (MA): Cambridge University Press, 1984.?

STREET, B. V. Literacy Practices and Literacy Myths. In: SALJO, R. (Ed.). The Written World: Studies in Literate Thought and Action. Berlin; New York: Springer, 1988. p. 59-72.

SWALES, J. M. Genre Analysis: English in Academic and Research Settings. Cambridge (UK): Cambridge University Press, 1990.

TOM, A. Teaching as a Moral Craft. New York: Longman, 1984.

UNSWORTH, L. Teaching Multiliteracies across the Curriculum: Changing Contexts of Text and Image in Classroom Practice. Buckingham: Open University Press, 2001.

VEIGA, M. Um perfil ético para educadores. Braga: Palimage, 2005.

VYGOTSKY, L. S. A formação social da mente. 6. ed. São Paulo: Martins Fontes, 2000 .

Recebido em 12/03/2012. Aprovado em 26/06/2012. 